Cad.Est.Ling., Campinas, 47(1) e (2):203-211, 2005

\title{
PARALELISMO Y PARÁFRASIS EN LA TEXTULIZACIÓN INFANTIL ORAL
}

\author{
LILIANA D. BARDONE \\ (Universidad Nacional de Rosario - Rca. Argentina \\ Grupo de Pesquisa em Aquisição da Linguagem)
}

\begin{abstract}
RESUMEN Este trabajo está encuadrado en la investigación que vengo realizando para mi Tesis Doctoral, con la orientación de la Dra. Pereira de Castro. El tema es la Paráfrasis en Adquisición del Lenguaje, considerado este fenómeno, el de la adquisición, desde la perspectiva interaccionista sostenida por Pereira de Castro, M.Fausta, De Lemos Claudia y otros investigadores brasileños.

Mis estudios acerca de la paráfrasis tomaron como punto de partida la concepción enunciativa sostenida por Fuchs (1994), en cuanto a pensar las relaciones de paráfrasis entre enunciados como un tipo de relación dialéctica entre lo mismo y lo diferente, más allá de los límites de la frase.

En el campo de la Adquisición del Lenguaje, el fenómeno parafrástico se muestra en los textos orales surgidos en las interacciones adulto niño, donde los significantes de uno vuelven a aparecer en los de su interlocutor, marcados por las diferencias. Es decir que las paráfrasis manifiestan la actividad interpretativa de ambos y la captura del sujeto por el lenguaje, constituyéndose a veces como enunciados que muestran a un hablante errático en su discurso, otras, guiando su texto. En ambos casos, la paráfrasis produce “efectos de sentido” y entre esos efectos podemos reconocer el de la argumentación,”...como contraponto à deriva que ela se insere em um determinado arrajno textual-discursivo, garantindo sentido e unidade..." Pereira de Castro, M.F., 2002)
\end{abstract}

\section{INTRODUCCIÓN}

Los estudios sobre adquisición del lenguaje que desde el año 1987 venía desarrollando en el ámbito de la UNR, en el equipo coordinado por la Prof. Norma Desinano desde un encuadre socioconstructivista, basados fundamentalmente en las perspectivas de Vigotsky y Bruner fueron reflejados en una ponencia que presentara en ocasión del X Congreso de la ALFAL en México. ${ }^{1}$ Ese trabajo tenía como objetivo estudiar las paráfrasis producidas por niños de 4 años cuando narraban un cuento. Allí, el énfasis estaba puesto en las reestructuraciones/ reformulaciones que desde el punto de vista sintáctico, los niños eran capaces de producir, teniendo en cuenta además aspectos sociolingüísticos, relacionados con los entornos culturales, el conocimiento del mundo y fundamentalmente el rol del adulto como "socio" del niño en la interacción. La bibliografía había sido de base Vigotskyana y Bruneriana en cuanto al concepto de interacción y rol del adulto en el aprendizaje, y en lo atinente al fenómeno parafrástico había partido de los estudios realizados

${ }^{1}$ X Congreso de la Asociacion de Lingüística de América Latina, Veracruz, México, 1993. 
por Poggi, I (1984) $)^{2}$. En esa oportunidad entonces, tuvimos la feliz coincidencia de compartir la Comisión de Lectura con las profesoras del IEL, Rosa Attié y Raquel Fiad, quienes muy amablemente nos invitaron a participar del Seminario sobre Adquisición que en el mes de junio de ese mismo año se realizaría aquí, en el IEL.

De esa manera fue que entramos en contacto con las Doctoras Lemos y Pereira de Castro, convirtiéndose esta última en Directora de la tesis Doctoral que realizo en el marco de la UBA, Argentina.

Las lecturas de los trabajos de ambas, así como de otros investigadores brasileños en relación con la Adquisición, la profundización de los estudios sobre la oralidad, el acceso a los textos de Milner (1989), fueron modificando el rumbo de la investigación al encontrar sustento teórico en una teoría lingüística que considera a la Adquisición como un proceso signado por el cambio (Lemos, 1992) y a la lengua materna como lugar de interpretación (Pereira de Castro, 1997). Es evidente que, viendo en el niño un sujeto de/en el lenguaje, en la adquisición un fenómeno entendido como captura y en la lengua, la función estructurante del habla infantil, la paráfrasis ya no podía ser considerada como lo había sido en el mencionado trabajo, una "estrategia" del hablante, y mucho menos "enseñable".

Por otra parte, en cuanto a la organización gramatical de la oralidad, trabajamos durante más de diez años de acuerdo con las categorías establecidas para la descripción del francés oral por la Dra. C.B. Benveniste ${ }^{3}$, y su equipo de investigadores de la Universidad de Axois en Provenza, corroboradas por las investigaciones de J. Manuel Trigo Cutiño ${ }^{4}$ sobre el habla de los niños de Sevilla, lo que nos llevó a encontrar en el análisis del habla de niños y adultos de la zona de Rosario, estructuras sintácticas caracterizadas como simetrías y paréntesis, de aparición regular y frecuente. El reconocimiento de las simetrías nos permitió observar que más allá de las características diferenciales que cada tipo pudiera mostrar, el eje de su constitución es la repetición a nivel fonológico, morfoléxico y sintáctico.

Avanzando en este análisis con miras a ir más allá de un estudio meramente descriptivo, advertimos luego que las simetrías no son otra cosa que aquellas construcciones paralelísticas, repetitivas o alternantes, descriptas desde la relectura de Jakobson, en los trabajos de C. Lemos (2000) y Lier de Vitto (1998), en relación con el habla del niño.

Hemos podido observar además, que muchas de las estructuras paralelas encontradas en los diálogos y narraciones sobre los que trabajamos, muestran semejanzas y diferencias entre uno y otro de los enunciados considerados paralelos, basadas en las repeticiones, sustituciones y combinaciones homonímicas o antitéticas que hablan del cambio entre un enunciado y otro y nos llevan a pensar en la relación entre paralelismo y paráfrasis.

${ }^{2}$ Poggi, I. "El texto como red de conocimiento: para una didáctica sistemática de la paráfrasis". Lingüística Testuali, Atti XV Congreso Internazionali di Studi. Roma, Bulzoni, 1984.

${ }^{3}$ Blanche-Benveniste, C. (1990) Le français parlé. Transcription et édition. Paris: Didier.

${ }^{4}$ Trigo Cutño, J. M. (1990) El habla de los niños de Sevilla. Sevilla: Alfar. 
Cadernos de Estudos Lingüísticos 47(1) e (2) - Jan./Dez. 2005

\section{ADQUISICIÓN, PARALELISMO Y PARÁFRASIS}

¿Por qué la teoría de Adquisición y las consideraciones sobre el paralelismo produjeron efectos en mis reflexiones sobre la paráfrasis?

En primer lugar, porque si entendemos el fenómeno caracterizado en la literatura con el término Adquisición, siguiendo a C. Lemos, como aquel proceso a través del cual aquel que no habla pasa a transformarse en hablante, a la lengua como el sistema reglado, portador de estructura pero también como posibilidad de transgresión, de equívoco, de falla (Milner, 1989) y que se manifiesta en el funcionamiento lingüístico como la "captura" del individuo, asujétandolo, transformándolo en sujeto de /en el lenguaje, no podemos dejar de considerar al cambio como un punto crucial del proceso.

Si por otra parte entendemos también desde la teoría, que ese funcionamiento se realiza sobre la base del interjuego de los dos ejes constitutivos de la lengua denominados por Saussure sintagma y paradigma y que desde la relectura de Jakobson realizada por Lemos son vistos como fenómenos metafóricos y metonímicos alrededor de los cuales todo enunciado se realiza, nos encontraremos otra vez con el concepto de cambio. Si además, como lo hemos podido reconocer mediante el análisis de numerosos textos de la oralidad, en ese funcionamiento aparecen estructuras paralelísticas, reconocibles en el mantenimiento y/o alternancia de posiciones sintácticas entre enunciados, será posible ubicar en ese cruce de conceptualizaciones un nuevo concepto de paráfrasis. Nuevo en el sentido de que, no será visto ya como el resultado de un procedimiento lógico, ni como producto de la actividad metalingüística, concepciones ambas que refieren a un hablante monitor de sus enunciados. Tampoco podremos pensar a la paráfrasis de acuerdo con los planteos de Fuchs (1994) cuando la define como una relación de parentesco semántico entre enunciados, ya que desde esa perspectiva, la paráfrasis sería un fenómeno visible en los enunciados que un hablante en tanto usuario del lenguaje "maneja" como recurso. En cambio, desde el lugar de cruzamientos entre cadenas latentes y cadenas presentes en el eje metafórico, y de desplazamientos combinatorios en el eje de la metonimia, la paráfrasis podría llegar a ser considerada como propia del funcionamiento lingǘstico de los sujetos en el lenguaje, y muchas veces manifiesta en los paralelismos constitutivos de ese funcionamiento .

Es decir que en las estructuras paralelas puede reconocerse la agitación que la paráfrasis provoca cuando los enunciados se replican pero a la vez se modifican y muestran la resonanacia de uno en el otro, a partir de las sustituciones y combinaciones entre elementos de un enunciado que se replican en otro, modificado, de manera que el segundo se constituye en paráfrasis respecto del primero.

La caracterización del paralelismo en tanto estructura reconocible por la vuelta de los enunciados sobre sí mismos en un movimiento propio del verso, según lo definiera Jakobson en sus estudios sobre poesía hebraica y china y sobre folklore uralo- altaico y ruso en Questions de Poétique (1973), es la que nos ha permitido dejar de lado el concepto de simetría, de valor puramente descriptivo, pero no explicativo. Porque cuando el autor ruso establece el significado etimológico de los términos prosa y verso, atribuyendo al primer término oratio prosa < prorsa< proversa "discurso que va hacia adelante" y versus "retorno" 


\section{BARDONE - Paralelismo y paráfrasis en la}

al segundo, sostiene que afectando a todos los niveles de la lengua, el artificio técnico y artístico de la poesía reside en los reiterados retornos, que no son otra cosa que repeticiones o vueltas sobre lo mismo ya sea a nivel fonológico, morfológico, sintáctico o semántico. En la misma línea, plantea también que "los modelos poéticos en los que ciertas similaridades entre secuencias sucesivas son obligatorias o se benefician con un alto grado de preferencia, se encuentran en todas las lenguas del mundo y se prestan muy bien a la vez al estudio del lenguaje poético y al análisis lingüístico en general." ${ }^{5}$

Estas estructuras paralelísticas se caracterizan por presentar un elemento matriz que tiene su semejante en la secuencia y variables en función del elemento matriz original y el recurrente, es decir que la similaridad entre enunciados permite reconocer en la repetición un principio, que lejos de conferir debilidad al texto, sirve para potenciar el valor de cada uno de los elementos comprometidos. Jakobson cita también la clasificación de Hightower acerca de los paralelismos por reiteración, sinonimia, antonimia, fenómenos todos de alguna manera presentes en la paráfrasis.

Además, si nos detenemos en la etimología de paralelismo y la de paráfrasis, podemos observar que: paralelismo deriva del griego $<<$ parállelos $>{ }^{6}$ construido morfológicamente por el prefijo de origen griego "pará-", que significa cerca de, y la raíz “ allos", que significa otro, ajeno; paráfrasis, por su parte, también se forma con el prefijo griego "pará-“ que a la vez que expresa la idea de ajeno, significa también próximo, de manera que etimológicamente ambos términos hablan de una estructura que está junto a otra, repitiéndola en el caso del paralelismo, marcada por el cambio en alguno de los niveles lingüísticos, en la paráfrasis, llamada a poner de manifiesto en lo mismo, lo diferente.

\section{PARALELISMO Y PARÁFRASIS EN TEXTUALIZACIONES NARRATIVA ORALES}

En trabajos anteriores, hemos podido dar cuenta de la presencia de paralelismos, portadores de paráfrasis, por un lado en textos surgidos de interacciones dialógicas, en las que el decir de un locutor se desliza repetido, invertido, sinonímico o antitético, en el de su interlocutor, en un movimiento continuo de retomar repitiendo y /o modificando a medida que el diálogo continúa, y por otra, en las textualizaciones monologales originadas en las narraciones que realizan los niños a partir de la escucha de un cuento, considerado como texto fuente. En este último caso, las estructuras paralelísticas se reconocen sobre la base de la confrontación entre aquel texto primero y el del niño. Éste es el caso de los registros que analizaré a continuación, en los que podremos ver cómo el paralelismo en general puede operar de acuerdo con la prevalencia de dos direcciones: una la del eje del sintagma que contribuye con la progresión lineal, horizontal del texto, y otra en torno del eje

\footnotetext{
${ }^{5}$ La negrita es mía.

${ }^{6}$ Moliner, M. Diccionario de uso del español. (1999) Madrid: Gredos. Edición en CD-Rom.
} 
Cadernos de Estudos Lingüísticos 47(1) e (2) - Jan./Dez. 2005

paradigmático, que hace a la densidad textual, sobre la base del retorno a la misma posición mediante la sustitución metafórica de los elementos que lo constituyen, y que pone de manifiesto al movimiento parafrástico entre uno y otro enunciado.

Los dos primeros ejemplos que voy a analizar, muestran al paralelismo constituyendo paráfrasis en el interior de los enunciados de los niños, que reformulan su texto , promoviendo su avance en el eje sintagmático:

En (1), podemos observar que el texto se desliza sobre la base de la relación tema/ rema, es decir a nivel sintagmático en un paralelismo, revelador de una paráfrasis marcada por la definización del artículo indefinido

(1) Estefanía (11 años)

en el lago donde él iba a pescar había un caballo de mar gigante/

$y$

todos los pescadores

el caballo de mar gigante

tenían miedo

Sin embargo la niña no logra escuchar que su enunciado es agramatical - el sintagma cumple la función de Objeto Indirecto y por lo tanto debería llevar la preposición "a” y así que impulsar la progresión textual .

Otras veces, el paralelismo actúa de acuerdo con la segunda dirección, la del eje del paradigma, de manera que el texto podemos decir que "crece" cobrando densidad y recién a partir de allí recupera la continuidad sintagmática, como puede verse en (2):

(2) Lis (8 años)

Tenía tanto miedo pero lo tuvo que hacer a la mañana

a la noche fue a pescar al caballo de mar

Es en los paralelismos del tipo de lo que muestran (1) y (2), cuando entre un enunciado y otro se produce algún cambio, que se hace presente el fenómeno parafrástico, que contribuirá para que el texto luego se deslice también sintagmáticamente hacia el encuentro del sentido y la consistencia.

Podemos ver entonces que la paráfrasis también dice algo acerca de la posición del sujeto en su relación con la lengua, y es desde este punto vista que la teoría de Adquisición también se explica como teoría del funcionamiento de los sujetos en el lenguaje, porque los cambios producidos por la paráfrasis pueden ser de dos órdenes: por un lado pueden mostrar a un sujeto que está en la lengua pero es impermeable al error (1) o bien como en el caso de (2) manifestar a un sujeto dividido entre aquel que habla, y aquel que se- escucha y puede reformular-se sacando su texto de la deriva. 
A continuación, podemos ver en (3) y (4) ejemplos en los que el paralelismo se reconoce entre un enunciado del texto original y uno del niño que narra el cuento previamente escuchado

(3) Romina (8)

el conejo hizo callar el tamborcito de su corazón

el conejo hizo parar el corazoncito de los tambor

Aquí ambos enunciados responden a idéntica organización sintáctica (SVO), pero son visibles entre ambos los cambios instaurados por una paráfrasis originada sobre la base de cruzamientos metafóricos entre parar y callar; tamborcito y corazoncito, corazón y tambor. También se operan desplazamientos de carácter metonímico entre tamborcito de su corazón y corazoncito de los tambor, es decir que los elementos del texto fuente operando como cadenas latentes, en el texto infantil se hacen presentes sustituyéndose metafóricamente y dislocándose metonímicamene, de manera que afectan al sentido del texto y también a los aspectos estructurales ya que el corazoncito de los tambor es gramaticalmente anómala. Sin embargo, el paralelismo se evidencia también entre corazón y tambor, donde la rima asonante se constituye, además por el agregado de aquel elemento que hace a la agramaticalidad en el sintagma los tambor, donde falla la concordancia de número pero los viene a completar una estructura trisílaba para tambor, que es bisílaba, restableciendo el paralelismo entre co-ra-zón y los-tam-bor, que además riman a través de la vocal "o" (corazón/lostambor), cosa que no hubiera ocurrido si el niño hubiera dicho del tambor, que es lo gramaticalmente esperable.

Éste es uno de los tantos ejemplos que ponen de manifiesto un paralelismo en el que surge la paráfrasis y una paráfrasis en la que el sujeto es impermeable a su propia escucha de manera que su texto deriva a partir de enunciados inesperados.

En el caso de (4), en cambio también se trata de una narración infantil y las paráfrasis aparecen en el enunciado del niño como reformulaciones sucesivas, que muestran a un sujeto que se-escucha y que logra sacar su texto de la deriva inicial:

\section{(2) Jorge (12)}

él cuando llegó con el caballo de mar apresurado en la red apreturado en la red que estaba apresado ya estaba como una presa llegó a la ciudad

El paralelismo aparece en las sucesivas repeticiones reformulativas que producen por un lado un efecto de detenimiento de la progresión textual, con un aumento de la densidad en el eje del paradigma, donde cadenas latentes empujan y se hacen presentes en el habla de un sujeto que puede dividirse entre aquel que habla y aquel que se-escucha y desde esa escucha es que puede llegar al significante pertinente, que permitirá la progresión sintagmática, como puede apreciarse en la siguiente transcripción en grilla. 
Cadernos de Estudos Lingüísticos 47(1) e (2) - Jan./Dez. 2005

el cuando llegó con el caballo de mar apresurado en la red apreturado en la red

que estaba apresado ya

estaba

como una presa

llegó

a la ciudad

Es decir que en casos como éste el paralelismo manifiesta a la paráfrasis producida por un sujeto que se escucha y advierte que su palabra no hace a la referencia porque en todo caso está significando otra cosa. Quiero tomar aquí las palabras de C. Lemos (2002) cuando dice que "también en la lengua la condición para referir es significar, es decir una operación que implica la remisión infinita de un significante a otro", para explicar cómo llega a referir Jorge una vez que el paralelismo que va surgiendo en su textualización, lo lleva de una paráfrasis a otra a partir de que se escucha, es decir que la relación entre su decir y la lengua se muestra en una tercera posición, la de la escucha. Porque lo que muestra este ejemplo es lo siguiente: Hay tres verbos puestos en juego a partir de diferentes relaciones gramaticales y fonológicas entre cadenas:

\section{Apresur-//-ar /}

Apret- //-ar/

Apres-//-ar/

Por un lado, atendiendo a la posibilidad de encontrar palabras bajo las palabras (Starobinsky) ${ }^{7}$, apresurar fonológicamente contiene a apresar que es el verbo pertinente al texto. Pero se interpone entre ambos, apretar vinculado con apresar y con apretar, por un lado por la semejanza fonológica y por otro semántica, ya que tener preso a alguien bien puede interpretarse como tenerlo apretado o viceversa. Es decir que es posible reconocer aquí un cruce entre cadenas latentes y cadenas presentes, que se detiene a partir de que el niño se escucha, advierte la falla y reformula su enunciado.

Desde el punto de vista morfológico también se producen cruzamientos porque:

Apresurar $\longrightarrow$ apresurado

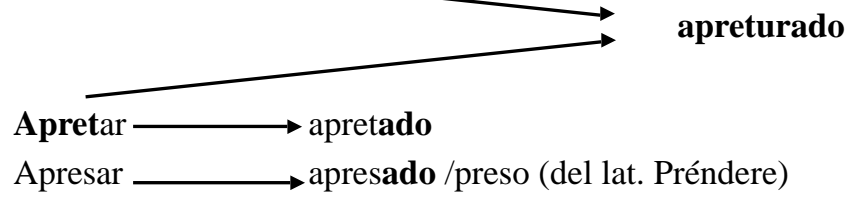

${ }^{7}$ Starobinsky, J. (1996) Las palabras bajo las palabras. La teoría de los anagramas de Ferdinand de Saussure. Barcelona: Gedisa. 
Primero, aparece como elemento inesperado apresurado, proveniente de la sustitución metafórica entre apresurado y apresado. Luego, también inesperado: apreturado que no pertenece a la lengua ya que se trata de un elemento que surge de la sustitución del fonema - $s$ - por - $t$ - que proveniente de la raíz de apretar y se desliza en un movimiento metonímico hacia la raíz apresurar, hasta que finalmente surge apresado que pone de manifiesto una escucha propia de la $3^{\text {a }}$ posición en la última reformulación: como una presa.

\section{A MODO DE CONCLUSIÓN}

Los análisis realizados en esta presentación, me permiten considerar que el paralelismo, surgido del interjuego entre los ejes paradigmático y sintagmático, se desliza entre la metáfora y la metonimia en un movimiento de alternancia entre lo mismo y lo diferente, que define de alguna manera el concepto de paráfrasis que, como resonancia entre enunciados instaurada por la sinonimia, la antítesis, la síntesis, se revela en los textos surgidos de prácticas lingüísticas dialogales y monologales. En ellas, se visualiza la paráfrasis como un fenómeno propio del funcionamiento lingüístico de los hablantes en la continuidad de los textos dialógicos y monológicos y se la descubre en el reconocimiento de los paralelismos como figuras sintácticas reveladoras de la función estructurante de la lengua en el discurso.

Por otra parte, si en el hilo del discurso hay sucesión en relación con las dos líneas definidas como similitud y contigüidad, líneas que a su vez necesariamente implican cadenas latentes e inhibidas en función de la selección operada, los efectos de este funcionamiento, que muestran las huellas del texto oral, son constitutivos del fenómeno parafrástico. Es decir que la paráfrasis podría ser considerada como un movimiento determinado por la presencia de un habla otra que cataliza el sentido del texto en la conjunción de las operaciones de sustitución (a nivel paradigmático) y combinación (a nivel sintagmático), poniendo de manifiesto el cambio entre un enunciado considerado fuente y su paráfrasis. Ambos constituirían conjuntos analógicos definidos así tanto por los significantes involucrados como por los efectos de sentido logrados y la continuidad textual alcanzada o no.

\section{BIBLIOGRAFÍA}

FUCHS, C. (1994). Paraphrase et Énonciation. Paris: Ophrys. (1982). La paraphrase. Paris: Presses Universitaires de France.

JAKOBSON, R. (1973). Le parallélisme grammatical et ses aspects russes. In Questions de Poétique. París: Éditions du Seuil. pp. 234-279.

De Lemos, C.T.G. (2002). Das vicissitudes da fala da criança e de sua investigação. ORLANDI, E. (org.) Cadernos de Estudos Lingüísticos. História das idéias lingüísticas, $\mathrm{n}^{\circ}$ 42, Campinas, SP, pp. 41-69, Jan./Junho 2002. 
De Lemos, C.T.G. (2000). Sobre o paralelismo, sua extensão e a disparidade de seus efeitos. Versão preliminar do trabalho a ser apresentado na Mesa-Redonda sobre Aquisição e Patologia, coordenada por Maria Francisca Lier-de Vitto, Quinto Encontro Nacional sobre Aquisição de Linguagem Primeiro Encontro Internacional Porto Alegre, PUCRS, 2 a 6 de outubro de 2000.

. (1992). Procesos metafóricos y metonímicos como mecanismos de cambio. Substratum I-1, pp.121$135,1992$.

Lier de VitTo, M.F. (1998). Os Monólogos da criança: Delírios da Língua. São Paulo: Cultrix.

MILNER, J.C. (1998). El amor de la lengua. Madrid:Visor. . (1989). Introduction à une science du langage. Paris: Éditions du Seuil.

PEREIRA DE CASTRO, M.F. (2002). A argumentação na fala da criança: entre fatos de língua e de discurso. Ponencia presentada en el Congreso Internacional: La argumentación.Buenos Aires, julio de 2002. . (1997). A Interpretação: A Fala Do Outro e A Heterogeneidade Da Fala Da Criança. L.E.T.R.A.S, No 13, organizado por Scherer, A.E. y Coracini, M.J.- Revista del Maestrado en Letras de UFSM (RS). Janeiro / Junho. pp. 125-138. 